\title{
Consumption effect of an aging population--Taking Hangzhou as an example
}

\author{
Rong $\mathrm{Li}$ \\ Zhejiang Business College 310053, Hangzhou, China \\ IrIr1212@sina.com
}

Keywords: an aging population; the consumption structure; grey correlation degree; Hangzhou.

\begin{abstract}
With the development of society and economy, social life expectancy widely extended, the aging of the population trend is increasingly highlighted. Due to differences in physiological and psychological aspects of the elderly in the characteristic of consumption habits and consumption tendency is obvious. In the current global economic downturn generally, facing domestic industrial structure adjustment, under the condition of ageing of consumption is becoming the important force to boost the economy in a period in the future. Research on aging to improve social consumption, leading the upgrading of industrial structure has an important significance. In this paper, Hangzhou as the research object, from 2003 to 2015, on the basis of the time series data using the grey correlation analysis method, study the influence of Hangzhou the consumption structure of the aging of population. Through the comparison and analysis, we found that an ageing population makes the consumption of society to pay more attention to the quality of life, concern on health care, education, culture and tourism consumption direction.
\end{abstract}

\section{Introduction}

As a common problem faced by humans in twenty-first Century, the aging population has become more and more concerned by the society. As a developed capital city in the southeast coast, Hangzhou in 1987 has entered the aging society (according to the traditional standard of the United Nations, the population of over 60 years old in an area reached $10 \%$ of the total population, which means it entered the aging society). Because of the significant difference of elderly consumers' demand compared with the other groups, with the constantly deepening of the population aging, the increase of elderly consumers' demand is bound to have a profound impact on the consumption structure of Hangzhou. According to the statistics from Hangzhou Municipal Commission of Health and Family Planning, the average life expectancy of the population in Hangzhou city has been from the age of 78.39 in 2003, increased to 81.85 years old in 2015 (in 2015, the Hangzhou household population is expected to live up to 81.85 years old. Http://n.cztv.com/news/12029738.html). Hangzhou population aging trend is obvious, and the proportion of the elderly population is increasing. The impact of aging population on consumption is increasingly prominent. With the increasing aging of the population, it is bound to have a greater impact on social consumption, and thus affect the economic operation of the whole society.

From the demand point of view, the aging of the population will have a certain restriction effect on consumption. The aging of the population on the one side changes the social consumption structure and consumption level, on the other hand, because of the decreased pay ability of the elderly population and it is bound to have a certain inhibitory effect on the consumption demand. At the same time, as the major consumer groups of medical services, the aging population will improve the structure of medical consumption, the adjustment of industrial structure of the whole society as well as it influences the health care, pension services and social security. And then it lead to the re-allocation of capital to promote the development of the aging industry and the emerging service industry.

\section{Research Review}

The aging of the population will have a far-reaching impact on the economic and social 
development, including the impact on consumption. Modigliani put forward the life cycle hypothesis in 1954, which think that consumers will optimize the configuration of their expected income of their life in different ages in order to maximize the effectiveness. The impact of population aging on economic development began from a book on the aging of the population and its social and economic significance in 1956, published by the United Nations. The book studies the effects of population aging on economic participation, social demand, and consumer distribution by using a stable population approach. Clark and Spengler in1980 took a sample survey and found that in some parts of the United States, the cost the government used to raise the elderly population is 3 times of that of young people. Hurd in1993 believed that with the increase of the elderly population in society, the total savings rate of society will decline while the cost of personal transport of the elderly will decrease and the health care spending will increase. Luhrmann in 2005 studied the German elderly influence on consumption structure and he found entertainment consumption and living expenses proportion increased significantly, while the proportion of food and clothing consumption expenditure decreased significantly.

The research of domestic scholars on the relationship between the aging of the population and the consumption started late. Wang Dewen in 2004 refered to the statistical model of Loew to fit the Chinese panel data which found that the elderly dependency ratio has a negative impact on the savings rate, and the acceleration of the aging population will weaken the contribution rate of population change to savings. Yuan Zhigang and Song Zheng in the paper of "the age structure of the population and the endowment insurance system and the optimal savings rate" in 2008 took the numerical simulation method to draw the conclusion that an important cause of the significant decline in the consumption tendency of urban residents is the age structure change. Wang Xia, etc. in 2011 used the other provincial panel data from 2002 to 2008 to study the effect of consumption caused by the aging process and found that there was a negative impact on the consumption of the change of elderly dependency ratio. Study on population aging influence on consumption, Yu Xiao and Sun Meng in 2012 put forward a new view that the impact of population aging on consumption will change continuously along with the change of aging process. Based on the survey data of household income and the input and output in China from 1988 to 2007, Zheng Yanyan and so on in 2013 studied the influence of the aging on urban consumption. They pointed out that aging promotes urban household consumption, and aging has great influence on education and entertainment service consumption, transportation and communications, health care and housing.

Study on the impact of population aging on consumption structure is primarily based on qualitative analysis and the quantitative analysis is as well limited to the relationship with the aging population and consumption demand. But in fact, the changes in the consumption demand of the elderly will affect the consumption structure of the whole society. Therefore, it is necessary to further study the impact of aging of the population on the consumption structure. Li Hongxin and Gao Wei in 2008 for the first time applied grey correlation theory to the impact of population aging on consumption structure. By comparing the relevance size of different age groups for different types of consumption, it determined the impact of aging population on different types of consumer goods.

\section{Trend of population aging in Hangzhou}

From the total elderly population, the elderly population in Hangzhou showes a gradual increase trend. By 2015, the total elderly population is more than 1 million people, up to 1 million 10 thousand and 100 people and by 2030, it is reaching 2 million 145 thousand and 400 and by 2045, reaching 3 million 188 thousand and 300. From the elderly population growth rate: there is a turning point in the elderly population, that is, 2030. Before 2030, the elderly population in Hangzhou increases year by year, and the growth rate is still high and after 2030, although the elderly population is still increasing year by year, but the growth rate decreased. It also can indirectly reflect Chinese family planning policy implementation steps. In late 60s last century, the country began to advocate family planning policy, and to $70-80$ s, it advocated 'late-dilute-less' fertility policy, and later it advocates the policy that a couple can only have one child, which 
causing the gradual convergence trend of new population after 1965. (In 2030, 65 year old population was born in 1965) (Table 1 and figure 1).

Table 1 2011-2015 Hangzhou population age structure

\begin{tabular}{|c|c|c|c|c|c|c|c|c|}
\hline \multirow[b]{2}{*}{ Year } & \multicolumn{2}{|c|}{ under 18 years old } & \multicolumn{2}{|c|}{ 18-35 years old } & \multicolumn{2}{|c|}{ 35-60 years old } & \multicolumn{2}{|c|}{ Over 60 years old } \\
\hline & $\begin{array}{l}\text { number } \\
\text { ( } 10 \\
\text { thousand) }\end{array}$ & $\begin{array}{c}\text { proportion } \\
\%\end{array}$ & $\begin{array}{l}\text { number } \\
\text { (10 } \\
\text { thousand) }\end{array}$ & $\begin{array}{c}\text { proportion } \\
\%\end{array}$ & $\begin{array}{l}\text { number } \\
\text { (10 } \\
\text { thousand) }\end{array}$ & $\begin{array}{c}\text { proportion } \\
\%\end{array}$ & $\begin{array}{l}\text { number } \\
\text { ( } 10 \\
\text { thousand) }\end{array}$ & $\begin{array}{c}\text { proportion } \\
\%\end{array}$ \\
\hline 2011 & 104.76 & 15.2 & 178.54 & 25.9 & 287.8 & 41.8 & 118.02 & 17.1 \\
\hline 2012 & 105.26 & 15.1 & 177.55 & 25.5 & 289.18 & 41.6 & 123.72 & 17.8 \\
\hline 2013 & 106.46 & 15.2 & 175.52 & 25.1 & 289.03 & 41.3 & 129.51 & 18.5 \\
\hline 2014 & 107.01 & 15.1 & 173.19 & 24.5 & 289.77 & 41 & 136.64 & 19.3 \\
\hline 2015 & 110.19 & 15.4 & 171.22 & 23.9 & 289.44 & 40.4 & 144.91 & 20.3 \\
\hline
\end{tabular}

Source: Hangzhou statistical yearbook

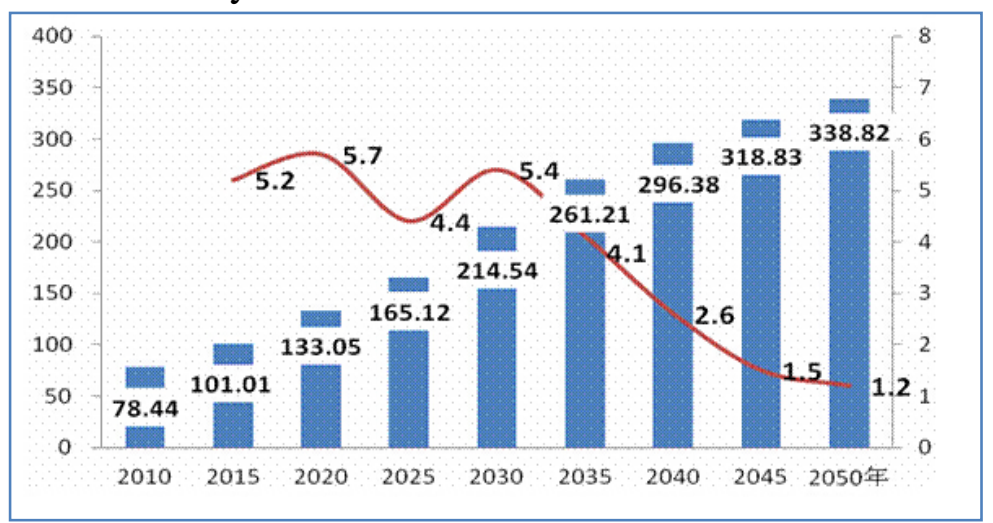

Figure 1 2010-2050 Hangzhou elderly population (10 thousand people) and growth rate (\%) Data selection, model construction, the principle introduction of grey relational degree.

\section{Influence of population aging on consumption structure in Hangzhou}

\subsection{Model construction}

The gray correlation degree refers to the different or similar degree of different factors' development trend. It is a way to measure the degree of correlation between the factors through the grey correlation degree. The advantage of the analysis is that the sample size is small and the data is not required to have a typical distribution of the law, and the amount of calculation is small. By analyzing the grey correlation degree of changes of population age structure and the consumption structure change of residents, this paper examines the impact of the acceleration of population aging on the consumption structure of the residents.

First define the parent sequence and sub-sequence, the time series of the population of all ages accounted for the proportion of the total population in this paper is defined as the parent sequence: Y1 represents 0 to 18 year old population, Y2 represents 18 to 35 year old population, Y3 represents 35 to 60 year old population, Y4 represents population over 60 year old. All kinds of consumption proportion of residents of the overall consumption is defined as sub-sequence: $\mathrm{X} 1$ represents food, X2 represents clothing, X3 represents housing, X4 represents household equipment and services, X5 represents medical care, X6 represents transport and communications, X7 represents entertainment, education and culture, X8 represents other goods and services. Then, the 
grey relational degree model is established, and the grey correlation degree between the parent sequence and the sub sequence is calculated and studied.

\subsection{Data selection}

According to the statistical yearbook of Hangzhou City, this paper selects the time series data of Hangzhou from 2011 to 2015 and calculates the corresponding data, see table 2:

Table2 2011-2015 Consumption structure of urban residents in Hangzhou

\begin{tabular}{c|c|c|c|c|c|c|c}
\hline $\begin{array}{c}\text { food } \\
\mathrm{X}_{1}\end{array}$ & $\begin{array}{c}\text { clothing } \\
\mathrm{X}_{2}\end{array}$ & $\begin{array}{c}\text { housing } \\
\mathrm{X}_{3}\end{array}$ & $\begin{array}{c}\text { household } \\
\text { equipment and } \\
\text { services } \mathrm{X}_{4}\end{array}$ & $\begin{array}{c}\text { medical } \\
\text { care } \mathrm{X}_{5}\end{array}$ & $\begin{array}{c}\text { transport and } \\
\text { communications } \\
\mathrm{X}_{6}\end{array}$ & $\begin{array}{c}\text { entertainment, } \\
\text { education and } \\
\text { culture } \mathrm{X}_{7}\end{array}$ & $\begin{array}{c}\text { other goods and } \\
\text { services } \mathrm{X}_{8}\end{array}$ \\
\hline 33.59 & 9.7 & 8.9 & 4.97 & 5.9 & 19.72 & 13.76 & 3.47 \\
\hline 34.26 & 10.09 & 7.94 & 5.13 & 5.79 & 19.25 & 12.25 & 3.06 \\
\hline 34.57 & 10.47 & 7.43 & 5.43 & 6.11 & 18.24 & 13.78 & 3.97 \\
\hline 35.05 & 9.79 & 7.2 & 5.39 & 5.7 & 19.19 & 13.91 & 3.77 \\
\hline 34.43 & 9.61 & 8.62 & 6.02 & 5.35 & 19.64 & 14.48 & 4.07 \\
\hline
\end{tabular}

4.3 Empirical analysis

(1) Matrix X= (Y4, X1, X2, X3, X4, X5, X6, X7, X8) T, where Y4, X1,X2 .. X8 are column vector of five year data as shown below.

$\mathrm{X}=\left\{\begin{array}{rrrrr}17.1 & 17.8 & 18.5 & 19.3 & 20.3 \\ 33.59 & 34.26 & 34.57 & 35.05 & 34.43 \\ 9.7 & 10.09 & 10.47 & 9.79 & 9.61 \\ 8.9 & 7.94 & 7.43 & 7.2 & 8.62 \\ 4.97 & 5.13 & 5.43 & 5.39 & 6.02 \\ 5.9 & 5.79 & 6.11 & 5.7 & 5.35 \\ 19.72 & 19.25 & 18.24 & 19.19 & 19.64 \\ 13.76 & 14.48 & 13.78 & 13.91 & 12.25 \\ 3.47 & 3.06 & 3.97 & 3.77 & 4.07\end{array}\right]$

(2) Taking the urban elderly population data as an example, this paper uses the initial value operator to find the initial value of the sub-sequence, and gets the initial image $X$ '.

$\mathrm{X}^{\prime}=\left\{\begin{array}{lllll}1 & 1.0409357 & 1.08187 & 1.128655 & 1.18713 \\ 1 & 1.0199464 & 1.02918 & 1.043465 & 1.02501 \\ 1 & 1.0402062 & 1.07938 & 1.009278 & 0.99072 \\ 1 & 0.8921348 & 0.83483 & 0.808989 & 0.96854 \\ 1 & 1.0321932 & 1.09256 & 1.084507 & 1.21127 \\ 1 & 0.9813559 & 1.03559 & 0.966102 & 0.90678 \\ 1 & 0.9761663 & 0.92495 & 0.973124 & 0.99594 \\ 1 & 1.0523256 & 1.00145 & 1.010901 & 0.89026 \\ 1 & 0.8818444 & 1.14409 & 1.086455 & 1.17291\end{array}\right]$

(3) Getting the absolute value sequence matrix $\mathrm{Z}$ of the difference between the initial value of $\mathrm{X} 1, \mathrm{X} 2 \ldots \mathrm{X} 8$ and $\mathrm{Y} 4$ and the components.

$\mathrm{Z}=\left[\begin{array}{rrrrr}0 & 0.0209893 & 0.0527 & 0.08519 & 0.16213 \\ 0 & 0.0007295 & 0.00249 & 0.119377 & 0.19641 \\ 0 & 0.1488008 & 0.24704 & 0.319666 & 0.2186 \\ 0 & 0.0087425 & 0.01068 & 0.044148 & 0.02413 \\ 0 & 0.0595797 & 0.04628 & 0.162553 & 0.28035 \\ 0 & 0.0647693 & 0.15692 & 0.155531 & 0.19119 \\ 0 & 0.0113899 & 0.08042 & 0.117754 & 0.29687 \\ 0 & 0.1590913 & 0.06222 & 0.0422 & 0.01422\end{array}\right]$

(4) Taking $M$ as the largest element in the matrix $Z$, that is, $M=0.319666$, takes $m=0, \lambda=0.5$, the correlation coefficient rij $=(\mathrm{m}+\lambda * \mathrm{M}) /(\mathrm{Zij}+\lambda * \mathrm{M})$, and get the correlation coefficient matrix $\mathrm{r}$.

$r=\left[\begin{array}{lrrrr}1 & 0.8839233 & 0.75205 & 0.652319 & 0.49644 \\ 1 & 0.9954567 & 0.98466 & 0.572448 & 0.44866 \\ 1 & 0.5178726 & 0.39283 & 0.333333 & 0.42236 \\ 1 & 0.9481389 & 0.93734 & 0.783568 & 0.86882 \\ 1 & 0.7284582 & 0.77547 & 0.495781 & 0.3631 \\ 1 & 0.7116266 & 0.50459 & 0.50682 & 0.45533 \\ 1 & 0.9334791 & 0.66528 & 0.575795 & 0.34997 \\ 1 & 0.5011628 & 0.71979 & 0.791125 & 0.91828\end{array}\right\}$

(5) Takes the average value and it can obtain the grey correlation degree between X1, X2,..., X8 and Y4 namely:

$(\mathrm{r} 1$, r 2, r 3, r 4, r 5, r 6, r 7, r 8, $)=(0.76,0.8,0.53,0.91,0.67,0.64,0.7,0.79)$

It can be seen that the magnitude of the degree of relevance of the elderly population to the consumption structure of the urban residents: $r 4>r 2>>r 8>r 1>r 7>r 5>r 6>r 3$. The results show 
that the demand degree of the elderly population on different consumer in turn is as follows: the household equipment and services, clothing and other goods and services, food, entertainment, education and culture, health care, transportation and communication and housing.

\section{Conclusions and related policy recommendations}

"Consumer demand determines production", and the evolution of industrial structure is driven by the change of demand structure. Changes in consumer demand is the most direct and fundamental reason for the evolution of industrial structure. Overall, the aging of the population has affected the number and structure of the supply of labor in Hangzhou, which restricts the social and economic development, and has an inhibitory effect on social consumption. But through the study we also found that, because Hangzhou is located in the economically developed areas, where has strong attraction for talents. Talent flow can better make up for the problem of labor shortage caused by the aging of the population. By the analysis of Hangzhou's aging population and consumption structure, we also found that: with the aging of the population, the future consumption market of the elderly population in Hangzhou has great potential to develop. To increase the development of aging consumer market investment, and constantly open up the aging consumer related industries have a brilliant future. Based on this, the author puts forward the relevant countermeasures and suggestions.

(1)In the current situation of prominent excess capacity problem and the lack of effective demand, the positive development of the aging industry is conducive to the formation of a new growth point of consumption. This is not only a new export for the transfer of excess capacity and social investment opportunities, but also helps to improve the existing industrial structure to transfer the population pressure into economic opportunities. The "silver industry" from the birth of the aging population not only help solve the livelihood problems of reality, and may become a new bright spot to promote structural adjustment and growth, which is beneficial to the optimization and transformation in economy and the promotion of social employment. Therefore, we should actively explore the silver market, and accelerate the development of the aging industry according to the present situation of the expanding demand of elderly consumers.

The calculation of the gray correlation degree shows that the increase of the number of the aging population has a great influence on the development of educational culture and entertainment industry. Due to the more abundant and diversified demand of elderly in the field of spirit, it provides more opportunities for the elderly tourism industry and the elderly entertainment industry. Government should give more preferential policies in the development of the aging industry. On the one hand, it can promote production and consumption through the development of the aging industry and form related industrial chain. On the other hand, enterprises can also seize the opportunity of aging and approach to the aging industry, and actively develop relevant industries to obtain competitive advantage.

(2) Gradually improve the social security system, accelerate the combination of medical care, reduce the medical burden of the elderly and improve the elderly consumption capacity is another way. The acceleration of the aging put forward severe challenges on the existing social security system. Xi Jinping pointed out in the general secretary of the central financial and economic leading group meeting that it should crack the problem of medical support from the supply side. At the same time of expanding demand, we should focus on strengthening the structural reform from the supply side and focus on improving the quality and efficiency of the supply. Optimization of endowment service supply is to promote the integration of pension, medical and nursing resources. Through the integration of medical service mode, it can explore the innovation path of combining medical and pension and a new mode of cooperative medical institutions and pension, nursing institutions. Taking the insured population as the main objectives, and guiding its voluntary participation in the integration of medical care service system, and establishing a contractual service relationship with the basic medical and health service institutions can better meet the needs of diversified services for the elderly.

With the continuous expansion of the size of the aging population in Hangzhou, as well as the 
increasing consumption of health care in the elderly, it is bound to increase the demand for health care in the elderly population. From the medical expenses, the prevalence rate of elderly population is high, and therefore they bear the higher cost than other age groups. The impact of population aging on health care and pension security system is obvious. From the perspective of health care needs, the decline in the health of the elderly will increase the demand for health services. At the same time, it also has a greater impact on the social pooling fund to pay the medical costs. In order to make use of limited medical resources and promote the integration of medical care into the community, we should increase the construction of community medical and health service center.

Because Hangzhou's pension model is still dominated by home care, so the demand for the elderly population of the family doctor will gradually increase. With the development of economy and the improvement of the consciousness of social health, the average life expectancy of Hangzhou has been prolonged. More and more old people have begun to pay attention to the health care. Older people are more concerned about the physical health and quality of life and the need for health care products and related services is also increasing.

(3) With the development of economy and the progress of society, the demand for the consumption of cultural education and entertainment services in the elderly is also changing from the original material demand, and gradually shift to a higher level of spiritual needs. The old people's leisure consumption can be divided into many types. Such as learning consumption, many elderly people participate in elderly university learning and develop their own interests in it. In addition the free charge of museums and library in Hangzhou for the elderly has also attracted a considerable portion of the elderly. As for spirit consumption, like pets, music instruments, and there are also a lot of elderly people interested in tourism. Travel agencies in order to compete for the old customers, compete to launch a different destination elderly tour. As for recreational consumption, information age not only influence and change the young people's life; similarly, the elderly life is changing. Popularity of computer and intelligent mobile phone provides convenience for more elderly to know the world without getting out. In addition, the elderly in Hangzhou may have more opportunities to watch various types of entertainment and sports events, which also greatly enrich their lives from one aspect.

(4) It can adjust the economic structure through the aging population. Scientific use of aging forced mechanism, transforming from passive to active, can further improve the efficiency of social resources allocation. Due to the reduction of current total population of working age, coupled with prominent excess capacity problem, it indirectly pushes up the cost of labor. Increase of cost, and in turn forced the transformation of economic development mode and structural adjustment. This will promote the transfer of rural surplus labor force to the third industry, and promote the new development of the third industry. Although generally speaking, the new period of aging caused a slowdown and the inhibition effect on economic growth in Hangzhou, but it provides a forced mechanism to optimize and adjust the economic structure, realize the transformation of economic development pattern especially providing some favorable conditions in the adjustment and transformation of the structure of demand structure, the industrial structure, and the production factors structure.

Due to the change of the consumption demand and the adjustment of industrial structure caused by aging, it will have a greater impact on the market and social economic structure, forcing the original structure to adjust so as to adapt to the development of society and market demand. With the deepening of the aging process, it should seize the opportunity to promote the service industry development of the aging to create new employment opportunities for the society at the same time, the layout of the three major industrial will be more reasonable.

\section{Acknowledgement}

This paper is one of the research results of 2016 annual issues of the Zhejiang Institute of Business Economics (2016SJYB10) and the research result of the 2016 annual research project of Zhejiang Vocational College of Commerce (SZYYB201602).

Li Rong (1972- ), Male, from Huainan, Anhui Province, Master graduate student, lecturer of 
Zhejiang Vocational College of Commerce; research direction: problem of aging.

\section{References}

[1] Liangda. An ageing population have positive stimulating effect on consumption [N].Shanghai securities news,on May 6,2016;

[2] Wu Hangyuan, Zhou Zhaoxiong. Population ageing in zhejiang province to study the influence of residents'consumption structure[J].Rural economy and technology, July 25, 2015;

[3] Cuiwei. On the supply side with crack medical combination problem, xinhua net, December 7 , 2015;

[4] lulingLiu. An empirical analysis on the impact of population aging on residents' consumption structure[J].Journal of Beijing vocational college of labor security, June 25, 2015;

[5] Fan Xinge. Chongqing population aging [R].Research on the influence of the consumption structure of chongqing industry and commerce university master degree thesis, on May 18, 2014;

[6] GongYingHua, Du Jiyong, Song, Wenguang. Beijing population aging effect on consumption analysis [J].Journal of Beijing industrial vocational and technical college, on April 15, 2015;

[7] Li Tong, Li Mengying. Tianjin population aging research on the influence of the consumption structure [J]. Journal of modern business, June 18, 2015;

[8] Wei-wei wang. Nanjing population aging [J].The influence of the consumption structure of the Chinese and foreign entrepreneurs, January 5, 2015;

[9] Aihwa Wang. Population ageing in the new period of economic transformation path and the influence of coping strategies [J].Journal of social science in guizhou, February 6, 2013;

[10]Gaori. Shanxi development trend of population aging and countermeasure study [J].Journal of Shanxi agricultural university (social science edition, on July 15, 2012. 